\title{
Web Services for Transforming e-Cultural Heritage Management in Tanzania
}

\author{
Gloriana Joseph Monko \\ Nelson Mandela African Institution of Science and Technology (NM-AIST), Arusha, P.O. Box 447, Tanzania \\ E-mail: monkog@nm-aist.ac.tz \\ Khamisi Kalegele \\ Tanzania Commission for Science and Technology (COSTECH), Dar-es-salaam, P.O. Box 4302, Tanzania \\ E-mail: kalegs03@gmail.com \\ Dina Machuve \\ Nelson Mandela African Institution of Science and Technology (NM-AIST), Arusha, P.O. Box 447, Tanzania \\ E-mail: dina.machuve@nm-aist.ac.tz
}

Received: 12 September 2017; Accepted: 07 November 2017; Published: 08 December 2017

\begin{abstract}
Globally, applications of Information and Communication Technologies (ICTs) in services management and delivery have positively transformed various sectors of economies. Similar transformations have been witnessed in Tanzania, where mobile money and the Internet have transformed the way businesses are done. However, the transformations have not taken place across all sectors of the Tanzanian economy with some sectors lagging further behind than others. Cultural heritage sector, in particular, has been slow in leveraging ICT to transform the delivery of services. The sector is characterized by poor consumption of heritage sites and artworks, neglect, low publicity, weak branding, to mention a few. Although the achieved level of skills in Internet and Web have enabled the proliferation of many useful Websites which offer services to the public, information gathering remains a huge challenge considering the size of the country, its cultural heritage from 126 tribes and the vast nature reserves.

We have investigated the usefulness of Web services in promoting mechanisms to gather and disseminate information about e-Cultural Heritage in Tanzania. In our investigations, we analyzed stakeholders of the sector and realized that Web services can be used to foster mechanisms within specific groups using crowdsourcing techniques. We then proposed specific Web services that cater for information flow chain of Tanzanian's artwork industry and developed an e-cultural heritage portal for demonstration.

We tested the system with a sample of selected stakeholders and the initial results indicated that the locals' readiness for such a system is strong enough and that apart from developers benefiting from the Web services, accessibility of information and stakeholders' visibility will improve.
\end{abstract}

Index Terms-e-Cultural Heritage, Tourism, Web Mapping, Web services, Crowdsourcing, Tanzania.

\section{INTRODUCTION}

In modern societies where digital technology reigns supreme in facilitating delivery of human services, the term e-service has been created to refer to electronic services. In recent years, millions of people are using web for one or the other purpose and this number now has reached to its highest level [1]. The advent of Internet reshaped the promotion of tourism and cultural products and tourists' learning demands [2]. Continuous developments in the field of information and communication technologies (ICT) in our societies have changed how people access, share and use information [3] [4]. Due to the advancement of technology the digital landscape is constantly changing the cultural consumption and production patterns which force the cultural heritage industry to adopt the new technologies with regard to delivery, access and re-use of their digital heritage collections. Most of the developed countries have managed to digitize their cultural heritage centers for the purpose of increasing accessibility of information and making it available for all anywhere at any time regardless of distance and disabilities. [5] Stated that the need to create an e-culture environment arose from the undeniable fact that the cultural heritage of a nation defines it and therefore, should be disseminated to all, regardless of their location and their disability.

The objective of digitizing cultural activities is to provide e-content for education to local stakeholders and tourists as well as to provide e-learning and technical training for e-heritage which will help to achieve broader awareness and knowledge for cultural growth [6].

According to the World's Heritage sites statistics of July 2016, globally there are 1,052 heritage sites of which 814 are cultural, 203 natural and 35 mixed properties, in 165 states [7]. Out of 1,052 heritage sites, 96 are found in Africa. Tanzania is among the seven African countries 
with many heritage sites and the first in East Africa with seven world heritage sites [7]. Out of the seven heritage sites, three of them are cultural, three are natural and one is mixed properties [7]. However, Tanzania national emphasis and investment in cultural heritage is not substantial enough making the sector among of those that are left out. The sector suffers from low promotion and maintenance regardless of its importance in characterizing the identity of the nation. Most people are not aware of the cultural heritage sites and cultural materials present in our country making these sites receive only minimal attention from the public which in turn leaves the heritage sites in poor condition and eventual deterioration. With regard to historical sites, it is estimated that more than $70 \%$ of them are not in good condition while others are not well preserved and also in deterioration [8].

On top of that, many entrancing cultural heritage locations are hidden from tourists, especially When considering that the country is full of historic attractions which in turn makes them unpopular/unknown to many [9]. This makes unease for the tourists to discover them.

The management of cultural insights in museums, heritage conservation and art creation houses in the country is in desperate need of improvements, the systems in use are old in terms of design and technology with very low usability (poor access, less content) and are not integrated with one another. Although a lot of strides have been made by the government in improving ecultural heritage industry, more work still needs to be done. Among the various interventions, ICTs have not been particularly embraced enough in this sector of our economy.

Therefore, there is a need for a portal where researchers, scholars, teachers, tourists and the general citizenry can have easy access to information in our heritage institutions, visibility as well as contribute to the documentation of such cultural heritage sites. Cultural heritage preservation should be seen as an integral part of interrelated and dependent economic activities that extend from data collection, through knowledge transfer to educational systems, and lifelong learning.

In this research, we utilize web services technology to facilitate collection and acquisition of information using crowdsourcing techniques, which will allow the consumers to be engaged in giving ideas, and build social media campaign in promoting our cultural values [11] [12]. This will also improve the accessibility of information across the theme. The use of a mapping application system will also help to determine the locations of cultural heritage sites that are found in Tanzania. The digitization of cultural collections, combined with the increasing capacity of storage and Internet access to digital information will cause a rapid change in the traditional models of using, managing and accessing knowledge and information related to cultural heritage and artworks [13]. For that matter, a transformed e-cultural heritage industry will foster the cultural heritage business and subsequently magnify the economic contribution tourism makes towards the overall country's gross domestic product (GDP) [14]. The layout of this paper is as follows; after introduction, research methodology follows and thereafter results and discussion are covered before finalizing with a conclusion and acknowledgments.

\section{RELATED WORKS}

In this section we review literature material related to the problem discussed in this paper. The review is organized mainly in two major sections, which discuss the benefit of digitizing archives and solution towards making interoperable systems.

\section{A. Benefits of digitizing archives}

Several approaches have been made in order to improve cultural heritage centers such as museums by the help of ICT tools and different literatures have discussed about the internal as well as external benefits of digitizing archives. Several scholars explained how good digital archive could ease the work for curatorial staff, save space and preserve objects for future generations to enjoy. Digitization helps to get rid of limitations such as space, time, weight (e.g. for printed books) etc. at the same time proving access to vast information, contrary to conventional methods. According to one commentator, easy access is provided to cultural information and makes the information available for all complying with the logic (equal access and knowledge for all) [15].

The digitization of museum/archives is seen to have a great impact on cultural heritage since we have collection of documents and objects that are invaluable/ irreplaceable both culturally and monetarily. Usually, such items marked many turning points in modern history and need to be maintained due to their historical and cultural importance. Artworks that are recorded on papers are difficult to preserve and requires special environment to prevent destruction. By digitizing these documents more people can still have a taste of it for a much longer time scale in the near and distant future, contrary to the case if they were displayed in a heavily shielded case in a museum [16]. Digitization would also preserve cultural heritage in some visual form even when their physical reality has been completed destroyed by phenomena such as wars and natural disasters.

\section{B. Web services for interoperable systems}

Several studies discuss on how to improve information systems' integrations in different ways. One of the best solutions suggested by many is through web services. Web service is one of the latest technologies used for solving a problem of information system' integration [17] Web services are defined as software designed to support interoperable machine-to-machine interaction over a network by the World Wide Web Consortium (W3C). [17] Expounds how web services could be a huge solution due to its ability of making its components re-usable by offering application-components (like currency conversion, weather reports, or even language translation 
as services) and connecting existing software that can help to solve the interoperability problem by giving different applications a way to link their data.

Currently many electronic businesses, e-learning platforms and e-governance projects tend to apply web services in order to maintain robustness of their systems. Likewise, in this research web services technology is applied to save the same purpose as one way of solving a problem in the existing cultural heritage information systems in Tanzania. [17] further discusses the essential issues that enhance the robustness of applications based on web services; these include availability of the services, reliability, security and interoperability of applications. Furthermore, web service allows organizations to easily combine/integrate services across different organizations as well as within organizations. Such web-service-based integrated applications should guarantee consistent data manipulation and outcome of business processes running across multiple loosely-coupled organizations; hence, web services technologies should be expanded to equip with transaction-processing functionalities [18].

Despite of efforts made in Tanzania on improvement of our cultural heritage information systems, ICT is not well utilized in protecting and promoting this sector, therefore we set out to provide this tool as a solution for enhancing acquisition, discovery and accessibility of artifacts/artworks information in our museums/heritage centres for knowledge sharing and awareness of our cultural heritage. Besides, to the best of our knowledge there are no published works on this topic relevant to Tanzania which this work will help to narrow this information gap.

\section{RESEARCH METHODOLOGY}

A mixed research methodology was employed in our investigation and design activities. Stakeholder analysis approaches were used to gather knowledge about relevant actors so as to capture their information needs and the kind of influence they exert to the cultural heritage sector. The gathered knowledge then became key to designing the Web services using a top-down approach which is both modular and functional oriented. Experimental approaches were used to evaluate the functioning and usability of the services.

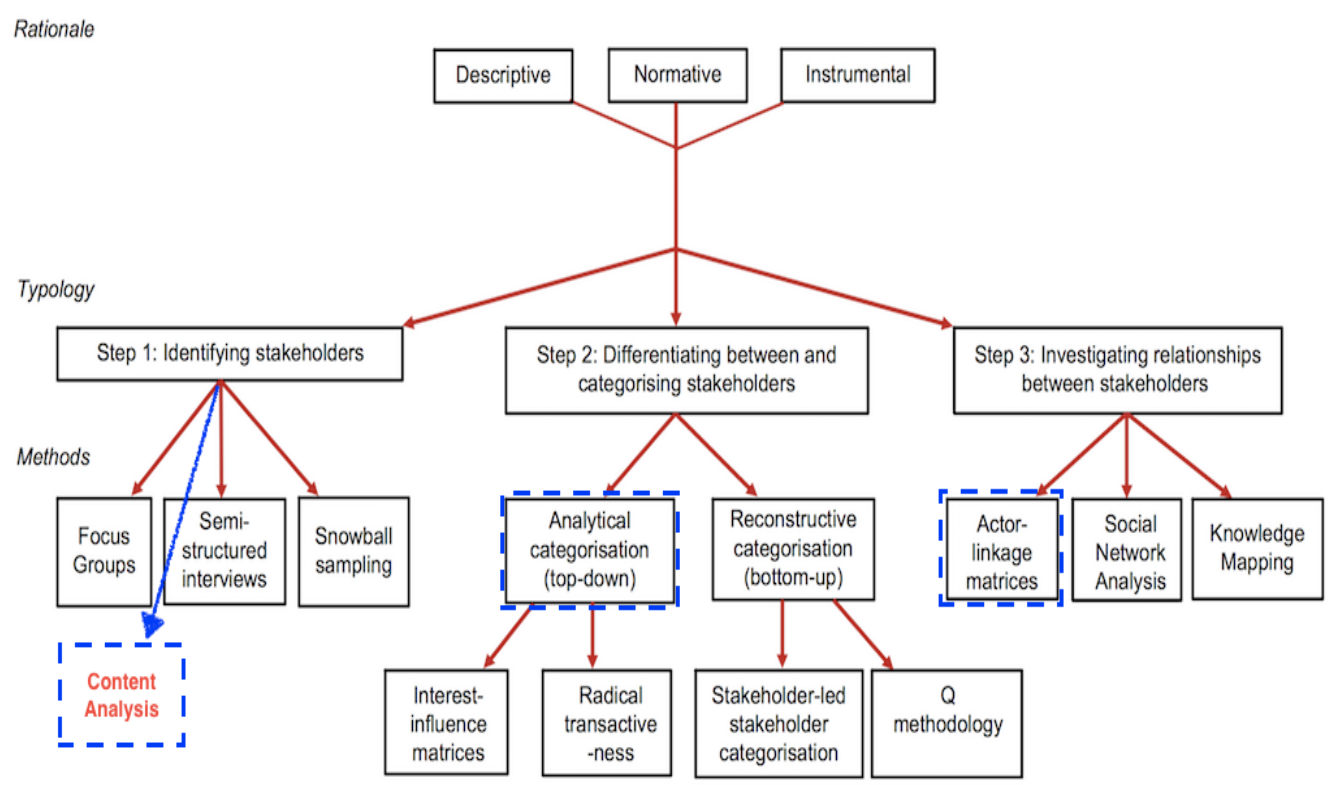

Fig.1. Modified Schematic Representation of rationale, typology and Methods

\section{A. Stakeholder Analysis}

The meaning of stakeholder analysis is quite subjective and over the years researchers have developed various methods and approaches for different purposes. In this research, we adopted with modifications the framework that was proposed by [19]. The framework mapped typical rationale for stakeholder analysis, topology and respective methods. Since the desire in our study was to gain insight, the descriptive rationale was found to be more relevant whereby the focus was to identify stakeholders, differentiate or categorize them, and lastly investigate existing relationships. In identifying the stakeholders, instead of using what [19] proposed i.e. either focus groups or semi structured interview or snowball sampling, we decided not to invent the wheel and conducted an analytical identification of stakeholders through content analysis of various reports and documents from authorities [20] [21] [22].

Fig 1 shows the schematic representation of the methods with the new one added to it. To categorize stakeholders, an analytical categorization approach was used. The approach used by [23] allows observations of a phenomenon (i.e. interactions between stakeholders) to be used in categorization based on factors like interest, competition, cooperation, roles, to mention a few. In this study, three factors were considered: interest, influence, and role. Table 1 summarizes these factors. To establish relationship an actor-linkage matrix was created and the interrelations described as either "business and service 
provision" or "regulation and law enforcement" or "support".

Table 1. Categorization Factors

\begin{tabular}{|c|c|}
\hline Categorization factor & $\begin{array}{c}\text { Description } \\
\text { or } \\
\text { dimensions }\end{array}$ \\
\hline Interest & Low, high \\
\hline Influence & Low, high \\
\hline $\begin{array}{c}\text { Role with respect to } \\
\text { information }\end{array}$ & Producer, broker, consumer \\
\hline
\end{tabular}

\section{B. Web services.}

The essence of using a top-down approach while ensuring modularity and functional organization is so that a wider range of people can later contribute to the proposed Web services (WS). This is also intended to accommodate the needs of our software development industry that is characterized by novice programmers. Thus, the specification of the overall system is first viewed as a black box with the major modules only, and then upcoming designers are allowed to decide how the internals of the lower level boxes should be. Functionally, modules or services are categorized as either registry or reporting or interactivity or mapping as presented in Table 2.

Table 2. Functional groups of Web services

\begin{tabular}{|c|l|}
\hline Service & \multicolumn{1}{c|}{ Description } \\
\hline \multirow{5}{*}{ Registry } & $\begin{array}{l}\text { Registration of vital information about artworks } \\
\text { and other cultural heritage sites. That is a collection } \\
\text { of the geolocation of sites that are crucial in the } \\
\text { cultural heritage industry and associated details. } \\
\text { The key registers will include markets/selling } \\
\text { points, art creation house, and museum/historical } \\
\text { site }\end{array}$ \\
\hline Reporting & $\begin{array}{l}\text { Retrieval of information such as popularity reports, } \\
\text { search services, and other reports. Additionally, the } \\
\text { retrieved information can be further processed and } \\
\text { integrated with information from other sources to } \\
\text { produce useful statistics. }\end{array}$ \\
\hline \multirow{5}{*}{ Interactivity } & $\begin{array}{l}\text { Capture of useful information from the public that } \\
\text { includes polls and comments through social media } \\
\text { and other gallery sites. This is a two-way } \\
\text { communication that is enabled by the prowess of } \\
\text { Web 2.0 whereby on one hand users get access to } \\
\text { information while on the other hand, they } \\
\text { participate in crowdsourcing activities to either } \\
\text { validate information or generate new information or } \\
\text { give opinion [13] [14]. }\end{array}$ \\
\hline $\begin{array}{l}\text { Provides directions for users (visitors/tourists) who } \\
\text { would wish to visit various cultural heritage sites. It } \\
\text { also provides quick details such as the type of } \\
\text { artifacts and services of a particular cultural } \\
\text { heritage site. }\end{array}$ \\
\hline
\end{tabular}

\section{Experimentation and evaluation}

To evaluate the designed services, prototypes were developed and tested. The objectives were to demonstrate that the proposed design works efficiently and to also conduct preliminary investigations on readiness and practicability of crowdsourcing technique of gathering information. One of the key functionalities of the developed prototype, e-Cultural Heritage portal, is geolocation of creation houses and cultural heritage sites. This mapping component of the e-Cultural Heritage portal was developed using services from the e-Cultural Heritage-WS which implements the designed Web services.

\section{RESULTS AND DISCUSSION}

\section{A. The cultural heritage and digital documentation requirements.}

The Conducted analysis confirmed that Tanzania is one of the countries with very rich heritage which is derived from its history, geography and the 126 tribes. There are about 19 different tangible artworks and sites, and about 9 different kinds of non-tangible heritage events. These are in no way exhaustive but rather those which have been well documented. Each of these was analyzed to establish ideal digital representation format and tools that can be used for capturing associated data as shown in Table 3.

\section{B. Key players or actors}

The key players who are involved in the Tanzania Heritage information ecosystem are the locals who engage in creation of various artworks (i.e. creation houses); citizens, clients and tourists who propose sites, buy artifacts and visit sites; The Government of Tanzania (GOT) which makes policies, regulate and protect, market places where business happens; museums where things are kept; and the international community through development partnerships, intercultural dialogues, and designation of special cultural or physical importance for protection. The information needs and contributions from each of the group of actors differ significantly. Fig 2 shows the key sets of information for each one of them in an ecosystem. Some groups of actors have been combined for convenience and also due to the fact that their information needs resemble to a large extent. For instance, tour companies have been considered as part of the market places, and preservation authorities have been considered as part of the Government. 
Table 3. Typical cultural heritage and documentation requirements

\begin{tabular}{|c|c|c|c|}
\hline Type & Example & Electronic format & Available Tools \\
\hline \multicolumn{4}{|l|}{ Tangible } \\
\hline Paintings & Kondoa Paintings, Tingatinga & Multimedia/picture & Cameras/phones/Scanners \\
\hline Drawings & Kondoa Paintings, Tingatinga & Multimedia/picture & Cameras/phones/Scanners \\
\hline Prints & Khanga, Vitenge, Makenzo, Vikoi etc. & Multimedia/picture & Cameras/Phones \\
\hline Mosaic & $\begin{array}{l}\text { Southern Zanzibar-Inhambane coastal } \\
\text { forest mosaic }\end{array}$ & Multimedia/picture & Cameras \\
\hline Sculptures & Makonde sculpture, Maasai sculpture & Multimedia/picture & Cameras/modeling tools \\
\hline Monuments & $\begin{array}{l}\text { Askari Monument, Arusha Mnara wa } \\
\text { Mwenge, Nyerere square }\end{array}$ & Multimedia/picture, map & Cameras/modeling tools \\
\hline Buildings & $\begin{array}{c}\text { Beit-al-ajab, BOMA in many districts, } \\
\text { Azania Front }\end{array}$ & Multimedia/picture, map & Drones/modeling tools \\
\hline Ruins & $\begin{array}{c}\text { Kilwa ruins, Mahurubi palace ruins, } \\
\text { Kaole ruins, Tongoni Ruins } \\
\end{array}$ & $\begin{array}{c}\text { High-resolution aerial Image, } \\
\text { map }\end{array}$ & Drones/satellites \\
\hline Town & $\begin{array}{c}\text { Zanzibar Stone Town, Bagamoyo, } \\
\text { Mikindani }\end{array}$ & $\begin{array}{c}\text { High-resolution aerial Image, } \\
\text { map }\end{array}$ & Drones/Satellites \\
\hline Archeological sites & $\begin{array}{c}\text { Olduvai Gorge, Isimila stone age, } \\
\text { Engaruka }\end{array}$ & $\begin{array}{c}\text { High-resolution aerial Image, } \\
\text { map }\end{array}$ & Drones/Satellites \\
\hline Photographs & $\begin{array}{c}\text { Ngorongoro crater, Serengeti Plains, } \\
\text { Lake Victoria, Mt. Kilimanjaro }\end{array}$ & Multimedia/picture, map & Scanners \\
\hline Documents & $\begin{array}{l}\text { Arusha Declaration, Recollections On } \\
\text { Mwalimu Julius Kambarage Nyerere By } \\
\text { Father Arthur H. Wille, M.M. }\end{array}$ & PDF & $\begin{array}{l}\text { Scanners, micro work } \\
\text { digitization technology }\end{array}$ \\
\hline Books & $\begin{array}{l}\text { The Maasai of Matapato: A Study of } \\
\text { Rituals of Rebellion }\end{array}$ & PDF & $\begin{array}{l}\text { Scanners, micro work } \\
\text { digitization technology }\end{array}$ \\
\hline Manuscripts & Chagga's rituals and sacrifices etc & PDF & $\begin{array}{l}\text { Scanners, micro work } \\
\text { digitization technology }\end{array}$ \\
\hline Instruments & Marimba, Drums, Horns, Zeze etc. & Multimedia/picture & Camera/Modelling tools \\
\hline Collection of objects & & PDF & Camera/Modelling tools \\
\hline Natural sites & Mbozi Meteorite, Amboni Caves & Multimedia/picture,map & Drones/Satellites \\
\hline Food & $\begin{array}{c}\text { Ugali, Mlenda, Makande, Matoke, tasty } \\
\text { Pilau, Nyamachoma }\end{array}$ & Multimedia/picture & Cameras/Phones \\
\hline Local beer & Mbege, Mnazi, Malovu, Kangara, etc & Multimedia/picture & Cameras/Phones \\
\hline \multicolumn{4}{|l|}{ Non-tangible } \\
\hline Traditions & Wedding, burial ceremonies & Multimedia/video & Cameras/Phones \\
\hline Dances & Ndali and matengo dancers & Multimedia/video and audio & Cameras/Phones \\
\hline Music & Taarabu, bongo flava,singeli etc. & Multimedia/video & $\begin{array}{l}\text { Cameras/Phones/Audio } \\
\text { recorders }\end{array}$ \\
\hline Excursions & Indian ocean fisherman & Map & Drones \\
\hline $\begin{array}{l}\text { Traditional knowledge } \\
\text { and practices }\end{array}$ & $\begin{array}{c}\text { Ancient irrigation systems, traditional } \\
\text { healer's diagnostic methods }\end{array}$ & PDF, Multimedia/picture & Drones/Satellites \\
\hline Performing arts & $\begin{array}{l}\text { Sindimba, Lizombe, Baikoko, Snake } \\
\text { Dance by Sukuma, Haya dance etc. }\end{array}$ & Multimedia/picture and video & Cameras/Phones \\
\hline Social Practices & $\begin{array}{l}\text { Tribal people return home during } \\
\text { Christmas, male Circumcision etc. }\end{array}$ & PDF & Cameras/Phones \\
\hline $\begin{array}{c}\text { Traditional } \\
\text { craftmanship }\end{array}$ & Sculpturers, Sewers, Traditional Dancers & PDF & Camera/Modelling tools \\
\hline Rituals & $\begin{array}{c}\text { Unyago, Jando, Chagga perform } \\
\text { sacrificial rituals to commemorate their } \\
\text { ancestors }\end{array}$ & PDF & Cameras/Phones \\
\hline
\end{tabular}

By identifying the key actors the ecosystem helps to elucidate how actors' engagement and relationships may influence management for the successful development of e-cultural heritage industry. It also reflects sets of activities done by each key player in the value chain and therefore how each can contribute to building an effective e-cultural heritage industry.

Arts creation houses are responsible for creating artworks creatively and in return, they receive revenue and use profiles and feedback, which form the basis for further improvements. Market places such as hotels, airports and art markets are advertisement areas and selling points of these artworks, through e-cultural heritage industry market houses are able to get fees commission's revenue. In this network, clients, as one of the stakeholders provide feedback via a system and pay fees when accessing the information. Among the different stakeholders, a key role is played by The Government, which strategically manages a system where other public, private and non-profit actors operate by laying down the policies, strategies for implementation and setting conservation regulations. The government also collects income tax from industry. One of the most important key players is Museums, they preserve, interpret and 
promote the tangible and intangible natural and cultural inheritance of humanity. By virtue of their role museums contain huge collections of artworks where people can have an easy access to them. As it is seen in Fig 2, the fee is paid whenever someone wants to access the museum collections. International heritage caretaker organization like UNESCO is there to encourage the integration of the preservation of heritage in urban and territorial development projects and ensures the inclusion of a social element to heritage conservation. They also act as a source of financial support through the International Monetary Fund (IMF) or the World Bank (WB).

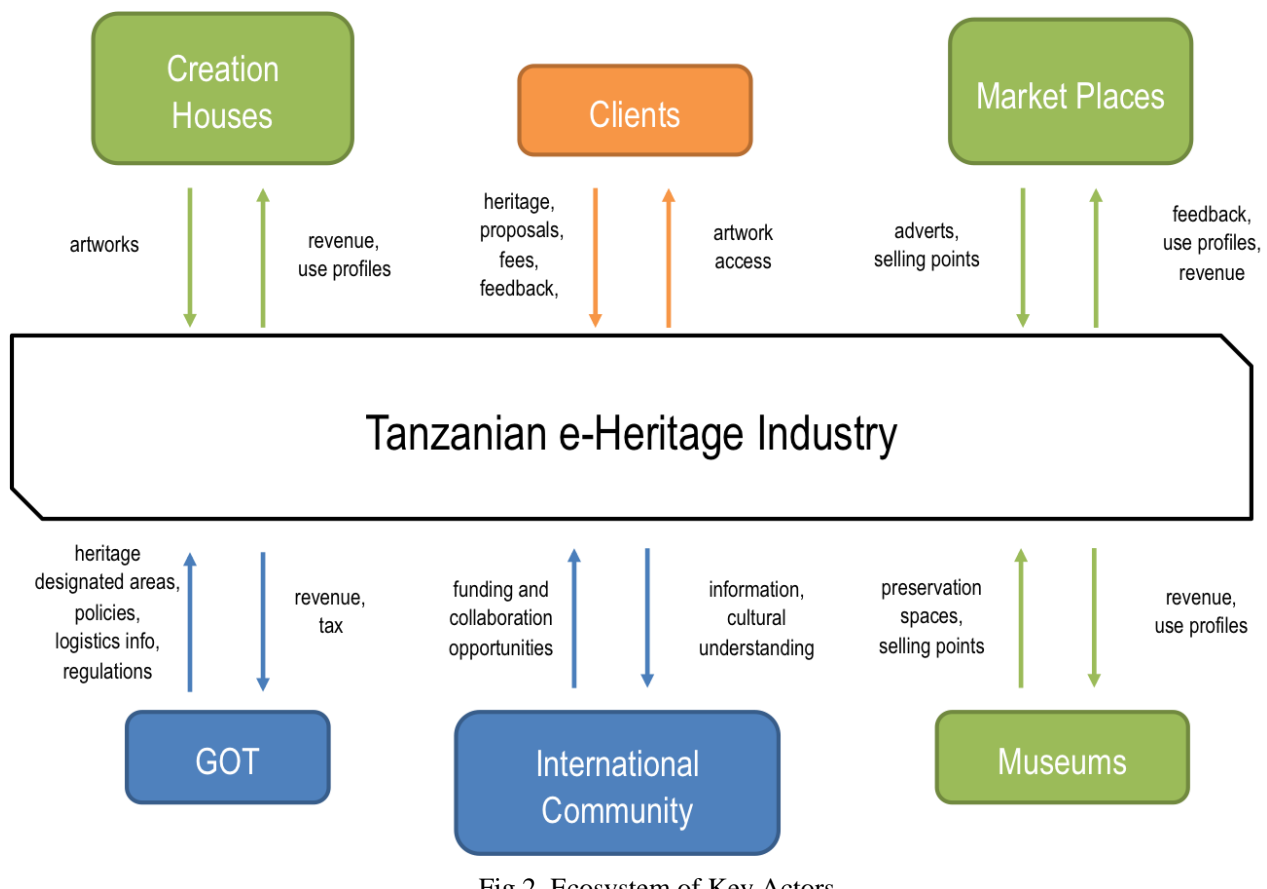

Fig.2. Ecosystem of Key Actors

\section{Categories of Actors and Relationships}

As explained in the methodology, actors were categorized using three factors: interest, influence and roles. From the conducted stakeholder analysis, a stakeholder Interest-Influence matrix which categorizes stakeholders in terms of their interest to information and influence was derived. By adding a third dimension, which represented the role factor, to the matrix, it was easier to extract relationships between actors. The information extracted from the matrix was organized into specific information spaces whereby for each, a special format $\mathrm{r}(\mathrm{tf})$ was used to describe role, interest and influence. In the $r(t f)$ format, $r$ is role, $t$ is interest, and $f$ is influence, whereas $t$ and $f$ can be either $\mathrm{H}=h i g h$ or $\mathrm{L}=l o w$ while $r$ can be either producer or broker or consumer. The matrix is presented in tabular form in Table 4. The sets of information as was presented in fig 2 are here classified into "administrative", "business" and "use" information spaces.

Table 4. Interest-Influence Matric in Tabular form

\begin{tabular}{|c|c|c|c|}
\hline Actor & Administrative Space & Business Space & Use Space \\
\hline Creation houses & Consumer/Broker (LL) & Producer (HH) & Consumer (HL) \\
\hline Clients and the public & Consumer (LL) & Consumer/Broker (LH) & Producer (HH) \\
\hline $\begin{array}{c}\text { Market places and service } \\
\text { companies }\end{array}$ & Consumer/Broker (HL) & Producer/Broker (HH) & Consumer/Broker (HH) \\
\hline The Government & Producer/Broker (HH) & Broker (LH) & Consumer (LH) \\
\hline International Community & Consumer/Broker (HH) & Consumer/Broker (HL) & Consumer/Broker (HH) \\
\hline Museums and art centers & Consumer/Broker (HL) & Producer/Broker (HH) & Consumer/Broker (HH) \\
\hline
\end{tabular}

The representation can also be used to infer the necessary actions to be taken in order to strengthen information flow and prosperity of the heritage industry. Fig 3 shows possible actions that can be taken for each of the interest-influence combination i.e. LL, LH, HL, and $\mathrm{HH}$. Citizens need to be monitored for change through provision of information on e-cultural heritage portal. One goal of this research will be to provide such a platform where citizens will be informed on the importance and utility of accessing, collecting and enjoyment of e-cultural heritage. On the other hand, the international community is hypothesized to be highly influential in changing the landscape of cultural heritage in Tanzania through their consumption while having minimal interest in developing it (as this is the nation's role). Our platform will keep the international community 
satisfied through provision of access to the Tanzania's ecultural heritage information. Stakeholders with both high influence and high interest are the government of Tanzania, museums, tourists and art creation houses. The e-cultural heritage platform will help these stakeholders gain greater access to a greater amount of e-cultural heritage materials through the constantly (and almost real-time) updated list of materials. Finally, stakeholders with high interest and moderately low influence include marketplaces, students and researchers. This platform will help keep them informed of the status of e-cultural heritage in Tanzania. We hope that through this platform eventually, all stakeholders will be moving to the high interest and high influence quadrant.

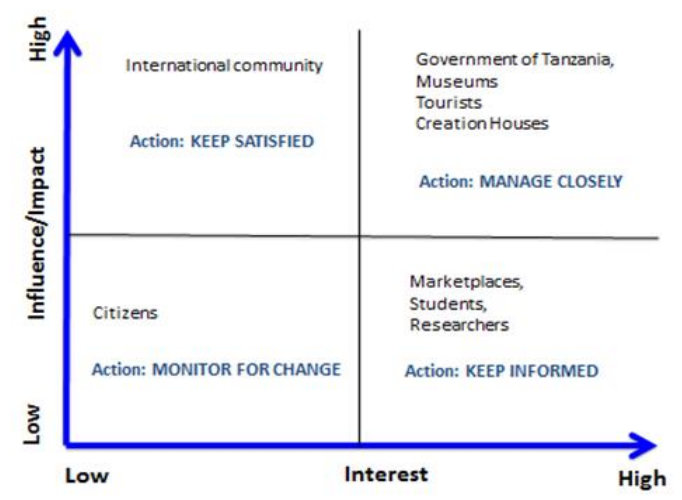

Fig.3. Matrix-Action mapping

\section{Web Services}

After understanding how each actor fits into specific roles and respective position within interest-influence matrix, a conceptual use case diagram and then an architectural diagram was prepared. Fig 5 shows the architecture together with a use case diagram (Fig 6), which shows the processes. Each of the processes in the use case diagram should implement the same architecture regardless of the information space (administrative or business or use).

In order to implement the web service architecture, we adopted the web service composition taxonomy as discussed by [24] but only concentrated on three service composition which is language, knowledge reuse and target user. The reason to why use only three of them is because they are the major key components in this study. Starting with language is the core dimension, which decides how composition occurs, which and how activities should be reinforced. Given its key role in the composition process language is further split into two sub-dimension and look at the different components and application targets the language may support [24]. This is well demonstrated in Fig 4.

The architecture follows the generic RESTFULL approach by considering all language service composition such as type of service, description, data format, interaction protocols, interaction style and selection to characterize the components [24].

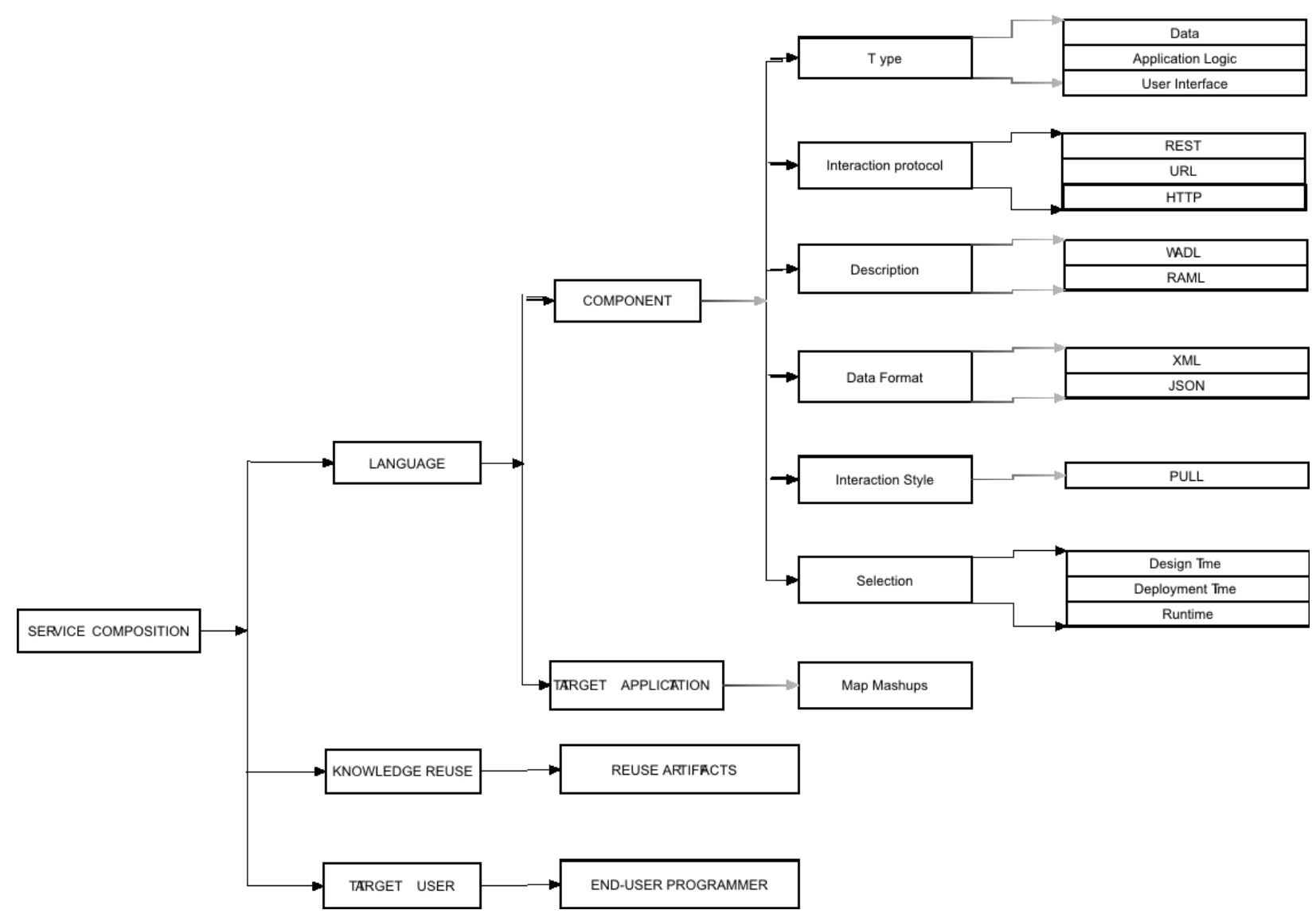

Fig.4. Web Service Composition for E-Cultural Heritage Portal 
Type: identifies whether the components will act as a data source, provide access to logic application or use Graphical User Interface (GUI) in rendering basic infrastructure services [24]. As of this study, a web service acts as a data source and provides access to other applications. The services provided in this architecture include registry service, reporting service, interactivity service and mapping service as indicated in Table 2.

Interaction protocol: Due to the fact that Representational State Transfer (REST) is an architectural pattern that exposes data and functionality through resources accessed via dedicated Uniform Resource Locators (URLs) over Hypertext Transfer Protocol (HTTP), in this architecture HTTP protocol is used as an interaction protocol for services to communicate and style of communication is done via Universal Resource Locators (URLs) where every communication is initiated.

Description: WADL/RAML are ways, which were used to describe the components. Web Application Description Language (WADL) use XML description of HTTP-based application [25], RESTful API Modeling Language (RAML) is a language for describing RESTful API [24]. The use of Web API (Application Program Interface) description is to allow the combination of the multiple web services into new single application which we call mashup. As an example, in this research, a map application developed use content from more than one sources to create a map mashup of cultural heritage sites' locations.

Data format: In the developed platform data format for service requests and responses is presented in eXtensible Markup Language (XML) and JavaScript Object Notation (JSON). Therefore it allows the program and scripts to dynamically access and updates the content, structure and style of these documents.
Interaction style: To support the communication between Client and Server in this architecture PULL style is used as an interaction style to allow a client/application to invoke the web services by following request-response pattern. This will only allow a client/application to access the services after the request is made by client/application.

Selection: The selection component describes the service composition life cycle that occurs in three different stages (i.e. design time, deployment time and runtime) [24]. Design time is when a developer chooses the services by selecting the actions which predefine the interaction with web services. Deployment time is the phase when the composition is deployed ready for execution and runtime is when composition is executed.

Knowledge reuse: Knowledge reuse is another web service composition which acknowledges the reused based nature, in our case the information provided relies on reuse artifacts. This allows adding existing artifact or creating new artifacts in the reused module.

Target user: Since the web service architecture intends to simplify the development of applications for developers the target users are the end-user programmer.

By identifying the key composition of the web service we arrived with an architecture for implementing the services. Fig 5 describes the interaction between REST server and client/ application by acquiring information from E-heritage database, which is collected from different sources such as mobile application, web application and other sources of the Internet. The RESTful web services will be accessed by an automated client or an application acting on behalf of the user. Conversely, this can be done by human interacting directly, which is done by constructing a GET URL with the web browser and read the content that is returned [26].

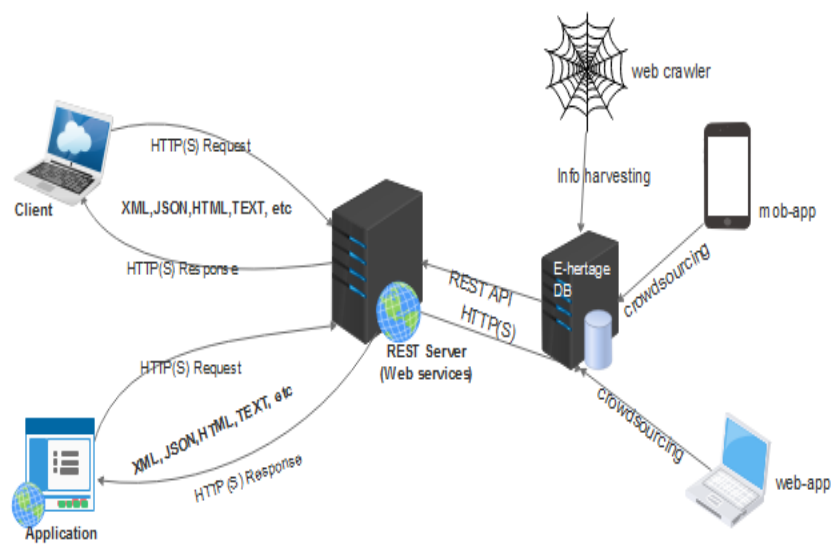

Fig.5. E-heritage Web Services Architecture 


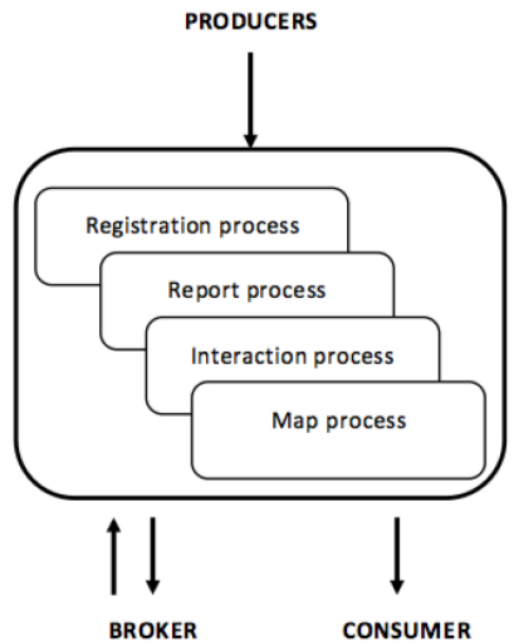

Fig.6. Use case Diagram

\section{E. Experimentation results.}

After the initial testing, we allowed selected stakeholders to manage their profiles while we observed their responses. The few selected stakeholders from three regions of Arusha, Dar es Salaam and Coast region were artwork creators from (Tingatinga Arts cooperative society, Ryno Carvings and Cultural Heritage), museum curators from (National Museum, Village Museum and Mambo ya kale Museum, Swahili for a Old Things Museum), Historical sites conservator from (Kaole ruins and Olduvai Gorge), arts galleries owners and sellers of cultural products from (Oldonyo Orok Arts and Gallery, Maasai Arts Gallery, Cultural Heritage, Trek Africa Art Gallery Kisongo Art Gallery, Masai Market, Tingatinga and Masai arts Gallery). They were able to do several registries as seen in Fig 7 and provide their locations (i.e. latitude and longitude) which later were deployed on the map.

For that reason, we were able to geolocate some cultural heritage sites in the three regions (Arusha, Dar es Salaam and Coast regions) as shown in Fig 8. The top panel (a) shows an example of mapped locations found in Arusha and bottom panel (b) shows mapped locations in Dar es Salaam and Coast regions.

By geolocating, these cultural heritage sites will solve a problem of discovering the hidden cultural heritage sites from tourists and make it easier for them to access their locations. Generally, the platform will be useful for people especially citizen to report undiscovered cultural heritage sites locations which will improve the documentation and eventually popularize them.

Fig 9 below shows the results of the request made by user after requesting a map service. It shows the communication, which takes place between Service Consumer (Client/user) and Service Provider (Web Server). A request made by client is passed on the URL where the connection between client and server occurs and then the communication is done over the HTTP protocol, the request is then sent to the server and returns the results to the client in an XML format document. All communications are accessible under presence of Internet. The document returned in an XML format can be reused in other applications that require the map service by the use of Application Program Interface (API). This simplifies works for other developers by avoiding rewriting of the code from scratch. Furthermore, it will enhance the integration of different system handling cultural heritage information.

\section{Services}

Choose a service that fits your needs.
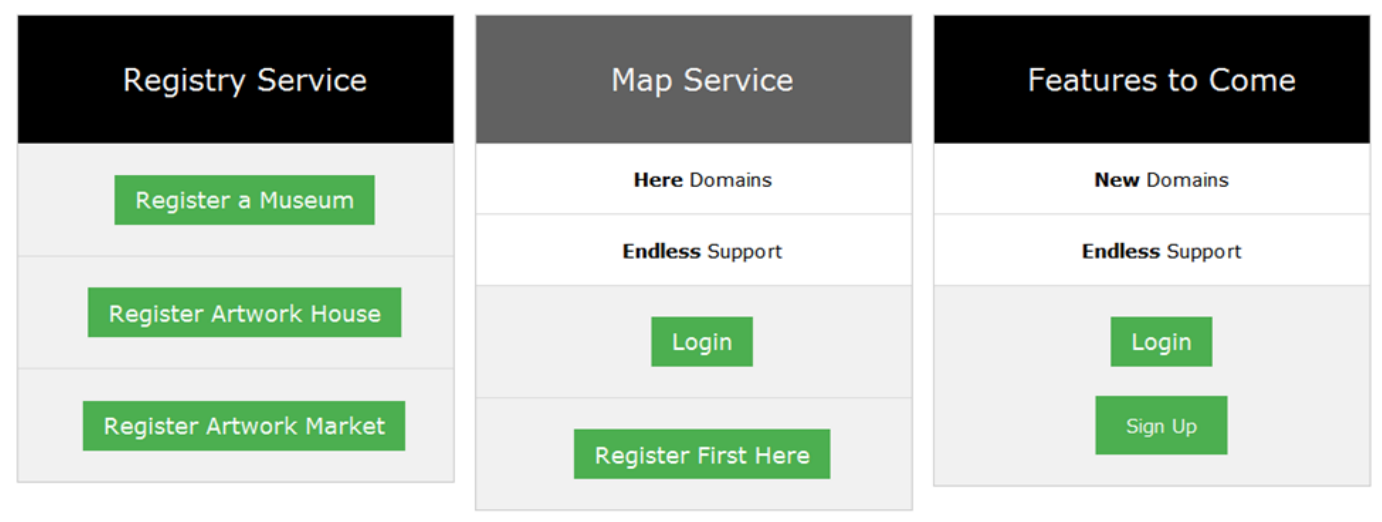

Fig.7. Web services 


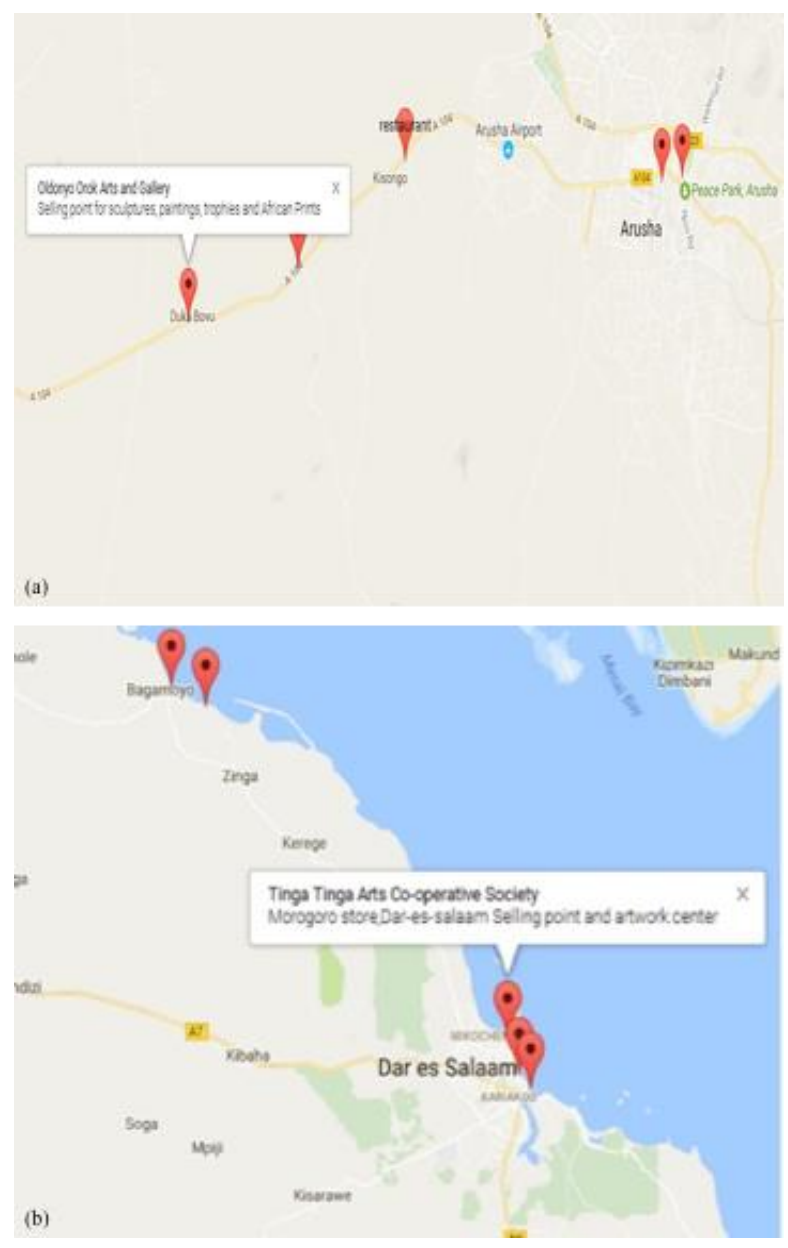

Fig.8. Example of mapped location in Arush (a) and in Dar es Salaam and Coast regions (b)

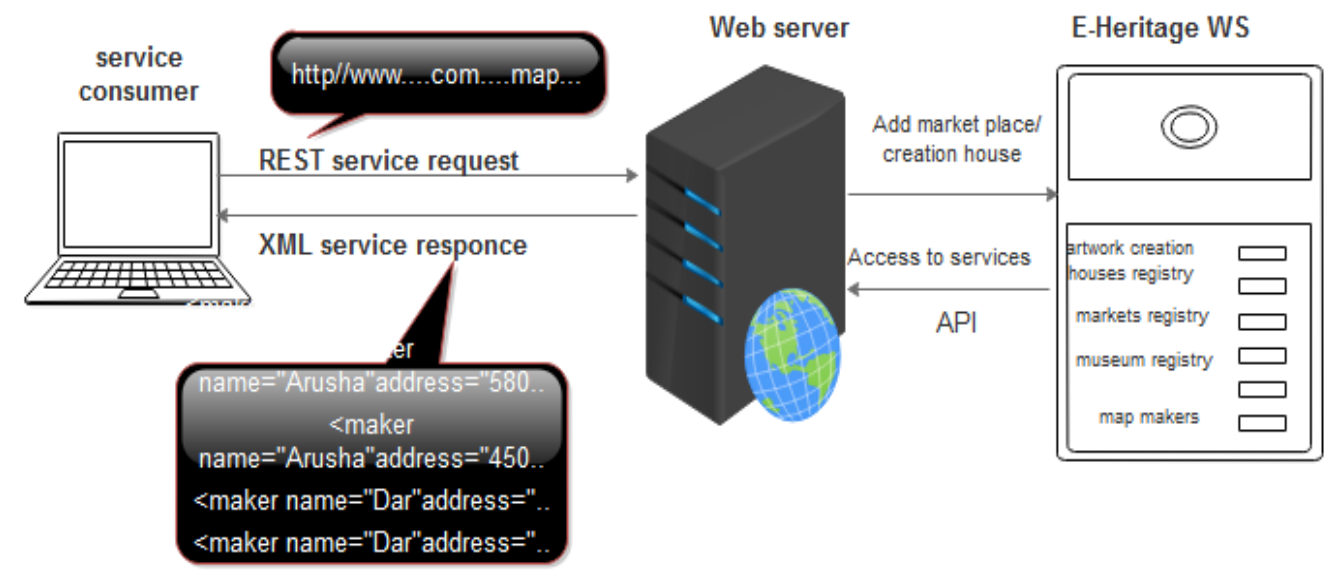

Fig.9. Example map service request

\section{CONCLUSIONS}

In this research, a Web Service for transforming eCultural Heritage industry of Tanzania has been designed and implemented. The motivation for employing web service architecture is to support interoperability of different applications and make the application components reusable. Initial evaluation of the design shows that users of the services are able to seamlessly utilize the services. In the evaluation that is ongoing, we expect a positive reaction from the stakeholders in contributing to the e-Heritage portal. It is not clear to which extent they are willing to be engaged but also the employment of crowdsourcing technique is expected to bring powerful results by involving the users in the process of documentation and promotion of cultural values through the interactive system. A completed portal will help to keep track of the dynamics of the industry and enable new studies that aim at improving information logistics. 


\section{ACKNOWLEDGMENTS}

We would like to extend our acknowledgments to the government of Tanzania through the Higher Education Students' Loan Board (HESLB) for funding this research and the University of Dodoma for granting an academic leave to the corresponding author.

\section{REFERENCES}

[1] R. Bibi, M. Jannisar, and M. Inayet, "Quality Implication for Prognoses Success in Web Applications," Int. J. Mod. Educ. Comput. Sci., vol. 8, no. 3, pp. 37-44, 2016.

[2] R. G. Connolly, D., Olsen, M. D., Moore, "The internet as a distribution channel.," in Cornell Hotel and Administration Quarterly, 1998, p. 39(4), 43-54.

[3] K. Taghandiki, A. Zaeri, and A. Shirani, "A Supervised Approach for Automatic Web Documents Topic Extraction Using Well-Known Web Design Features," Int. J. Mod. Educ. Comput. Sci., vol. 8, no. 11, pp. 20-27, 2016.

[4] R. M. Alguliyev and M. Rasmiyya Sh, "Information Culture Formation as the Most Promising Direction of Individual`s General Culture,” Int. J. Mod. Educ. Comput. Sci., vol. 7, no. 3, pp. 54-61, 2015.

[5] J. Glentzes, "An e-culture - e-museums environment for common citizens and disabled individuals," Int. J.of Digital Culture and Electronic Tourism, vol. 1, no. 4, 2009.

[6] F. M. Go, R. M. Lee, and A. P. Russo, "E-Heritage in the Globalizing Society: Enabling Cross-Cultural Engagement Through ICT," Inf. Technol. Tour., vol. 6, no. 1 , pp. 55-68, 2003.

[7] UNESCO, "UNESCO World Heritage Center - World Heritage List," 2016. [Online]. Available: http://whc.unesco.org/en/list/. [Accessed: 13-Nov-2016].

[8] Ministry of Communications Science and Technology the United Republic of Tanzania, "Research Priorities for Tanzania 2015 -2020,", United Republic of Tanzania, 2015.

[9] C. E. P. Armir Bujari, Matteo Ciman, Ombretta Gaggi, "Using Gamification to Discover Cultural Heritage Locations from Geo-tagged Photos," vol. 21, no. 2, p. pp 235-252, 2017.

[10] B. Vodopivec, R. Eppich, and R. Žarni, "Cultural Heritage Information Systems State of the Art and Perspectives," In Euro-Mediterranean Conference, Springer, Cham, pp. 146-155, 2014.

[11] R. Spiegel, "3 Ways to Benefit From Social Media Crowdsourcing," 2011. [Online]. Available: http://www.socialmediaexaminer.com/3-ways-to-dosocial-media-crowdsourcing/. [Accessed: 19-Jul-2017].

[12] G. Barbier and R. Zafarani, "Maximizing Benefits from Crowdsourced Data," Comput. Math. Organ. Theory, vol. 18, no. 3, pp. 257-279, 2012.

[13] E. Bertacchini and F. Morando, "The Future of Museums in the Digital Age: New Models of Access and Use of Digital Collections," no. 5, pp. 1-14, 2011.

[14] T. Rochelle, "Travel \& Tourism economic impact 2015 Tanzania," The authority on world travel \& tourism, 2015.

[15] A. S. Drigas, L. G. Koukianakis, and J. G. Glentzes, "A dynamical system for e-culture services," WSEAS Trans. Syst., vol. 5, no. 1, pp. 125-130, 2006.

[16] S. McDonough, J. P., Olendorf, R., Kirschenbaum, M., Kraus, K., Reside, D., Donahue, R., ... \& Rojo, "Preserving Virtual Worlds Final Report," Library
(Lond)., p. 195, 2010.

[17] A. Meligy, E. Elabd, and S. Kotb, "Web Services Privacy Preserving Based on Negotiation and Certificate Authorities,” Int. J. Mod. Educ. Comput. Sci., vol. 8, no. 10, pp. 49-55, 2016.

[18] S. Choi et al., "A framework for ensuring consistency of Web Services Transactions," Inf. Softw. Technol., vol. 50, no. 7-8, pp. 684-696, 2008.

[19] M. S. Reed, A. Graves, N. Dandy, H. Posthumus, K. Hubacek, J. Morris, C. Prell, C. H. Quinn, and L. C. Stringer, "Who' $\mathrm{s}$ in and why? A typology of stakeholder analysis methods for natural resource management," J. Environ. Manage., vol. 90, no. 5, pp. 1933-1949, 2009.

[20] I. Bakari, "Culture and Creative Industries in Tanzania: A Plan for Strategic Action,” Dar es Salaam, 2012.

[21] UNESCO, "Myanmar UNESCO Country Programming Document 2013-2015," Dar es Salaam, 2011.

[22] NSGRP, II, "National Strategy for Growth and Reduction of Poverty," 2010.

[23] Hare, M., \& Pahl-Wostl, C. (2002). Stakeholder Categorisation in Participatory Integrated Assessment Processes. Integrated Assessment, 3(1), 50-62. https://doi.org/10.1076/iaij.3.1.50.7408

[24] A. L. Lemos, F. Daniel, and B. Benatallah, "Web Service Composition: A Survey of Techniques and Tools," ACM Comput. Surv., vol. 48, no. 3, pp. 1-41, 2015.

[25] Hadley, M. J, "Web Application Description Language (WADL)". Search (Vol. 12). Retrieved from Retrieved from https://wadl.java.net/wad120061109.pdf, 2006

[26] B. Sun, "A multi-tier architecture for building RESTful Web services," IBM Dev. Work., pp. 1-7, 2009.

\section{Authors' Profiles}

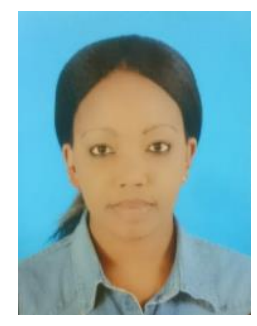

Gloriana J. Monko was born in Tanzania on $24^{\text {th }}$ September 1989. She is a student at the Nelson Mandela Institution of Science and Technology in Arusha, Tanzania, pursuing Masters in Information and Communication Science and Engineering. Studied Bachelor of Science in Informatics at Sokoine University of Agriculture (SUA) in Tanzania and has a strong background in Information Communication and Technology field. She is an employee at the University of Dodoma (UDOM) in Tanzania as a Tutorial Assistant.

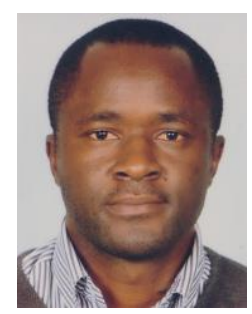

Khamisi Kalegele is an ICT specialist and a researcher, currently working for The Tanzania Commission for Science and Technology (COSTECH) as The Chief Research Officer but also as The Acting Director for Knowledge Management. He received his $\mathrm{PhD}$ in Information Sciences from Tohoku University in Japan, Master of Engineering in Computer Sciences from Ehime University in Japan in 2010, and Bachelor of Science in Engineering and Information Technology with Honors from The University of Dar es Salaam in Tanzania in 2003. He has a diverse background that includes industrial experiences in networking support, applications development, and telecommunication Engineering. Before working for the commission, he worked as a lecturer in the graduate school of information and communication science and engineering at The 
Nelson Mandela African Institution of Science and Technology in Arusha-Tanzania where he also successfully supervised a number of doctoral and master students, and as research fellow at The Flexible Information Center of The Research Institute of Electrical Communication in Sendai-Japan. His main interest in research and development activities lies in the novel and innovative application of information and communication technologies for socio-economic development of developing countries. He has ventured and developed solutions in various sectors including health, education, agriculture, water, transportation and now tourism.

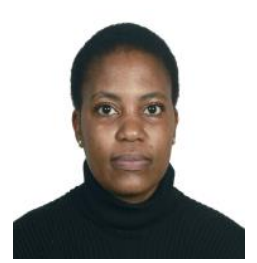

Dina Z. Machuve received her $\mathrm{PhD}$ in Information and Communication Science and Engineering from the Nelson Mandela African Institution of Science and Technology (NM-AIST), Tanzania in 2016. She is currently a Lecturer in the School of Computational and Communication Science and Engineering at NM-AIST. She is a technical committee member of Data Science Africa (www.datascienceafrica.org). Her research interests are data science, mobile applications development, agriculture Informatics on food value chains, electrical engineering and STEM education in schools.

How to cite this paper: Gloriana Joseph Monko, Khamisi Kalegele, Dina Machuve, "Web Services for Transforming eCultural Heritage Management in Tanzania", International Journal of Information Technology and Computer Science(IJITCS), Vol.9, No.12, pp.52-63, 2017. DOI: 10.5815/ijitcs.2017.12.07 